\title{
A comparison between hominy chop and defatted maize germ meal as the main energy source in diets of feedlot steers
}

\author{
K-J. Leeuw ${ }^{\#}$, H.H. Meissner ${ }^{1}$ and D. Palic ${ }^{2}$ \\ ARC-Animal Production Institute, Private Bag X2, Irene 0062, South Africa \\ ${ }^{1}$ Present address: 189 van Riebeeck Avenue, Centurion 0157, South Africa \\ ${ }^{2}$ Present address: Institute for Food Technology, Bulevar cara Lazara 1, 21000 Novi Sad, Serbia
}

\begin{abstract}
Defatted maize germ meal (DMG) is arbitrarily rated at a lower economic value than maize meal or hominy chop (HC). Five treatments with 15 steers each were fed different inclusion levels of DMG (0\%, $25 \%, 50 \%, 75 \%$ and $100 \%$ ), replacing hominy chop during the fattening period. Slaughter data were collected for carcass performance evaluation. DMG has lower fat levels and higher NDF (fibre) levels than HC. A slightly higher feed intake (8.1\% for T5 vs. T1) and lower gain (-4.4\% for T5 vs. T1) of steers on DMG containing diets resulted in a 9 to $14 \%$ poorer feed conversion ratio in comparison to steers on the HC diet. No differences were observed between carcass weights for all treatments and dressing percentage did not differ between T1 (57.4\%) and T5 (57.8\%). Pricing levels need to be adjusted to reflect the nutritional value of DMG.
\end{abstract}

Keywords: Economic value, steer performance, carcass performance

${ }^{\#}$ Corresponding author. E-mail: kleeuw@arc.agric.za

\section{Introduction}

The animal feeding industry, in particular the feedlot industry, estimates a 15 to 20\% lower (2004) (M. Savage, Personal communication, martins@ruto.co.za) economic value for defatted maize germ meal (DMG) in comparison to hominy chop (HC). This is based on the assumption that DMG will give a lower performance value (D. Ford, Personal communication, safa@safeedlot.co.za), since it contains less metabolisable energy than HC, which therefore implies that more DMG will be needed to fatten a feedlot animal. To test the validity of the assumption, feedlot steers in this study were to be fed either DMG or HC as the main energy component, employing a substitution design. Growth performance and carcass production were compared to facilitate an economic evaluation and calculation of a relative price for DMG. Therefore this study was done to establish whether prices paid for DMG are in line with its nutritive value (Savage, Personal communication).

\section{Materials and Methods}

Animal ethics approval was obtained from the Agricultural Research Council Animal Ethics Committee. Seventy five Bonsmara steers with an initial weight of $c a .190 \mathrm{~kg}( \pm 21 \mathrm{~kg})$ were blocked by weight into five treatments with 15 animals each. The steers were weighed, preventatively vaccinated against bacterial and viral diseases, treated for internal and external parasites, implanted with a growth hormone (Revalor $\mathrm{S}{ }^{\circledR}$ ) and given a numbered ear tag. The steers were housed in $2 \mathrm{~m}^{2}$ single stanchions fitted with a water drinker and feed trough. The trial period lasted for 124 days, whereafter the animals were slaughtered at a commercial abattoir where carcass weights and grading data were collected.

Formulated diets were similar to a commercial diet with an estimated $140 \mathrm{~g}$ crude protein $/ \mathrm{kg}, 100 \mathrm{~g}$ fibre/kg, $7 \mathrm{~g} \mathrm{Ca} / \mathrm{kg}$ and $4 \mathrm{~g} \mathrm{P} / \mathrm{kg}$. Treatment 1 (T1) contained only $\mathrm{HC}$ as main energy source; treatment 2 (T2) 75\% HC and 25\% DMG; treatment 3 (T3) 50\% HC and 50\% DFG; treatment 4 (T4) 25\% HC and 75\% DMG and treatment 5 (T5) only DMG (Table 1). During the trial period DMG and HC were delivered at different times and therefore the batches were sampled and analysed for nitrogen, fat, starch and NDF (AOAC, 2003). The steers were adapted to the final diet in 15 days, by reducing roughage content from $15 \%$ to $5 \%$ with $2 \%$ intervals every three days, while increasing the DMG and HC content of the respective diets correspondingly. 
Table 1 Ingredient composition (\%) of the diets in different treatments (T1 to T5)

\begin{tabular}{lccccc}
\hline Ingredient & T 1 & T 2 & T 3 & T 4 & T 5 \\
\hline DMG & - & 13.7 & 27.7 & 41.6 & 55.6 \\
HC & 55.2 & 41.4 & 27.7 & 13.9 & - \\
Wheat bran & 15.0 & 15.0 & 15.0 & 15.0 & 15.0 \\
Brewers grain (dried) & 9.0 & 9.0 & 9.0 & 9.0 & 9.0 \\
Molasses meal & 10.0 & 10.0 & 10.0 & 10.0 & 10.0 \\
Hay & 5.0 & 5.0 & 5.0 & 5.0 & 5.0 \\
Cotton seed (whole) & 3.0 & 3.0 & 3.0 & 3.0 & 3.0 \\
Feed lime & 1.6 & 1.6 & 1.6 & 1.6 & 1.6 \\
Urea & 0.5 & 0.4 & 0.3 & 0.2 & 0.1 \\
Salt & 0.5 & 0.5 & 0.5 & 0.5 & 0.5 \\
Vitamin/mineral premix & 0.25 & 0.25 & 0.25 & 0.25 & 0.25
\end{tabular}

DMG - Defatted maize germ meal; HC - Hominy chop.

T1 - energy source: 100\% HC; T2 - energy source: 75\% HC and 25\% DMG; T3 - energy source: 50\% HC and 50\% DMG; T4 - energy source: 25\% HC and 75\% DMG; T5 - energy source: 100\% DMG.

${ }^{1}$ Premix with vitamin A (6 million IU), vitamin B1 (3 g), antioxidant (3.5 g), monensin (33 g), iron (40 g), copper (12 g), zinc (50 g), cobalt (1 g), magnesium (200 g), manganese (40 g), iodine (1 g) and selenium (100 mg).

Data were analysed with the ANOVA statistical programme, GenStat (2000). Treatment means were separated using Fishers' protected t-test. Least significant difference (LSD) was accepted at the 5\% level of significance (Snedecor \& Cochran, 1980). DMG and HC feed conversion ratio (FCR) evaluation, in support of calculation of relative economic values, were estimated from regression analysis.

\section{Results and Discussion}

The results of the chemical analysis are shown in Table 2. As was expected, DMG had a lower fat level and a higher neutral detergent fibre (NDF) level than HC. The animal performance parameters are presented in Table 3. Non significant differences were observed for steer weight, average daily gain (ADG) and carcass grading. Feed conversion ratio $(\mathrm{FCR})$ differed $(\mathrm{P}<0.05)$ between treatments (Table 3$)$, with a clear advantage to treatment T1. The significant difference observed for dressing \% is probably due to the higher feed intake of steers in treatment $\mathrm{T} 2$ in the two weeks prior to the animals being slaughtered, resulting in higher digestive track fill for this treatment (data not presented). No significant difference in dressing \% due to differences between HC and DMG were recorded. In Table 4 the performance of steers on T2, T3, T4 and $\mathrm{T} 5$ was compared in relation to steers in treatment T1. Although not different $(\mathrm{P}>0.05)$, it is evident that a slightly higher feed intake and lower gain of steers on DMG containing diets resulted in a 9 - 14\% poorer feed conversion ratio in comparison to steers on the HC diet.

Table 2 Proximate analysis of energy sources used in trial $(\mathrm{g} / \mathrm{kg})$

\begin{tabular}{|c|c|c|c|c|}
\hline \multirow{2}{*}{$\begin{array}{l}\text { Source } \\
\text { Nutrient }\end{array}$} & \multicolumn{2}{|c|}{ Defatted maize germ meal } & \multicolumn{2}{|c|}{ Hominy chop } \\
\hline & Value & s.d. & Value & s.d. \\
\hline $\mathrm{n}$ & 6 & & 6 & \\
\hline Dry matter & 886.1 & 1.25 & 879.1 & 1.11 \\
\hline Crude protein & 103.3 & 1.19 & 92.5 & 0.95 \\
\hline Crude fat & 9.9 & 0.31 & 80.3 & 0.65 \\
\hline Starch & 451.9 & 3.20 & 456.9 & 3.07 \\
\hline NDF & 271.6 & 2.25 & 234.0 & 2.44 \\
\hline
\end{tabular}

NDF - Neutral detergent fibre; s.d. - Standard deviation. 
Table 3 Animal performance and carcass characteristics of the different treatments (T1 to T5) (calculations from linear regression)

\begin{tabular}{lccccccc}
\hline & $\mathrm{T} 1$ & $\mathrm{~T} 2$ & $\mathrm{~T} 3$ & $\mathrm{~T} 4$ & $\mathrm{~T} 5$ & $\mathrm{p}^{1}$ & s.e. $^{2}$ \\
\hline $\mathrm{n}$ & 12 & 13 & 14 & 15 & 15 & & \\
Initial weight (kg) & 188.6 & 182.0 & 188.6 & 186.4 & 187.31 & 0.937 & 21.4 \\
Final weight (kg) & 407.0 & 397.4 & 408.4 & 403.3 & 402.0 & 0.966 & 42.1 \\
ADWG (kg/steer/day) & 1.81 & 1.73 & 1.78 & 1.76 & 1.73 & 0.885 & 0.23 \\
FI (kg/steer/day) & 8.55 & 8.83 & 9.31 & 9.31 & 9.23 & 0.281 & 1.05 \\
FCR (kg/kg) & $4.71^{\mathrm{a}}$ & $5.13^{\mathrm{ab}}$ & $5.29^{\mathrm{b}}$ & $5.27^{\mathrm{b}}$ & $5.37^{\mathrm{b}}$ & 0.002 & 0.42 \\
Carcass weight (kg) & 233.5 & 223.8 & 235.2 & 233.9 & 232.3 & 0.781 & 24.9 \\
Dressing \% & $57.38^{\mathrm{ab}}$ & $56.28^{\mathrm{b}}$ & $57.58^{\mathrm{ab}}$ & $57.97^{\mathrm{a}}$ & $57.80^{\mathrm{a}}$ & 0.015 & 1.31
\end{tabular}

T1 - energy source: 100\% hominy chop (HC); T2 - energy source: 75\% HC and 25\% defatted maize germ meal (DMG); T3 - energy source: 50\% HC and 50\% DMG; T4 - energy source: 25\% HC and 75\% DMG; T5 - energy source: $100 \%$ DMG.

${ }^{1}$ Probability value at the $5 \%$ level; ${ }^{2}$ Standard error of the single unit; ${ }^{3}$ Average daily weight gain; ${ }^{4}$ Feed intake, as is; ${ }^{5}$ Feed conversion ratio; ${ }^{\text {a, b }}$ Row means with different superscript differ significantly at $\mathrm{P}<0.05$.

Table 4 Percentage differences of treatments T2, T3, T4 and T5 in relation to treatment 1 (T1)

\begin{tabular}{lccccc}
\hline & \multirow{2}{*}{$\mathrm{T} 1$} & $\mathrm{~T} 2$ & $\mathrm{~T} 3$ & $\mathrm{~T} 4$ & $\mathrm{~T} 5$ \\
\cline { 3 - 6 } & & \multicolumn{4}{c}{ Percentage differences } \\
\hline $\mathrm{n}$ & 12 & 13 & 14 & 15 & 15 \\
Initial weight $(\mathrm{kg})$ & 188.6 & -3.5 & 0.0 & -1.2 & -0.7 \\
Final weight $(\mathrm{kg})$ & 407.0 & -2.36 & 0.34 & -0.91 & -1.23 \\
ADWG $(\mathrm{kg} / \mathrm{steer} / \mathrm{day})^{1}$ & 1.81 & -4.42 & -1.66 & -2.76 & -4.42 \\
FI (kg/steer/day) & 8.60 & 3.27 & 9.07 & 8.95 & 8.14 \\
FCR (kg/kg) & 4.75 & 8.92 & 12.31 & 11.89 & 14.01 \\
Carcass weight $(\mathrm{kg})$ & 233.5 & -4.15 & 0.73 & 0.17 & -0.51 \\
Dressing \% & 57.38 & -1.92 & 0.35 & 1.03 & 0.73
\end{tabular}

T1 - energy source: 100\% hominy chop (HC); T2 - energy source: 75\% HC and 25\% defatted maize germ meal (DMG); T3 - energy source: 50\% HC and 50\% DMG; T4 - energy source: 25\% HC and 75\% DMG; T5 - energy source: $100 \%$ DMG;

${ }^{1}$ Average daily weight gain; ${ }^{2}$ Feed intake, as is; ${ }^{3}$ Feed conversion ratio.

To conduct an economic evaluation of the experiment, a price structure was used for the diets mixed (South African Rand - ZAR/1000 kg). DMG was taken as the unknown, HC was priced at ZAR 920.00, wheat bran at ZAR 900.00, brewers grain (dried) at ZAR 960.00, molasses meal at ZAR 850.00, hay at ZAR 800.00, cotton seed (whole) at ZAR 2 300.00, feed lime at ZAR 380.00, urea at ZAR 2 500.00, salt at ZAR 420.00 and vit./min. premix at ZAR 18000.00 . These were used to calculate the dietary costs for the various treatments and in the analysis shown in Table 5. T5 was used in comparison to T1 to calculate the amount that can be paid for DFG if HC costs ZAR 0.92 per kg (ZAR 920 per ton). The calculations are presented in terms of ZAR feed cost per $\mathrm{kg}$ of gain. The estimated cost for DMG per $\mathrm{kg}$ is $14 \%$ below that of HC $(0.79 / 0.92 \times 100)$, which coincides with the $14 \%$ difference observed in FCR between T1 and T5 (Table 4). This also seems to coincide with the 14\% difference observed in FCR between T1 and T5 (Table 4.). However, if a linear regression equation, which takes individual variation into account (Figure 1), is considered a $12 \%$ difference is calculated between $\mathrm{T} 1$ and $\mathrm{T} 5$ :

$(0.1453 \times 1)+4.7173=4.8626$ and $(0.1453 \times 5)+4.7173=5.4438$, with $((5.4438 / 4.8926)-1) \times 100=12 \%$. 
Table 5 Cost determination of the treatments, with DMG at ZAR 0.00

\begin{tabular}{|c|c|c|c|c|c|c|}
\hline Treatment & $\begin{array}{c}\text { Feed } \\
\text { cost } / \mathrm{kg}\end{array}$ & FCR & $\mathrm{R} / \mathrm{kg}$ gain $^{1}$ & c difference & $\begin{array}{l}\text { kg DMG in } \\
\text { FCR }\end{array}$ & $\begin{array}{c}\text { ZAR/kg } \\
\text { DMG }\end{array}$ \\
\hline T1 & 0.98 & 4.71 & 4.95 & & & \\
\hline T5 & 0.46 & 5.37 & 2.58 & 237 & 2.985 & 0.79 \\
\hline
\end{tabular}

DMG - Defatted maize germ meal; HC - Hominy chop; ZAR - South African Rand.

T1 - energy source: 100\% HC; T5 - energy source: 100\% DMG; FRC - Feed conversion ratio (kg/kg).

${ }^{1}$ Based on observed FCR, as opposed to predicted FCR from linear regression.

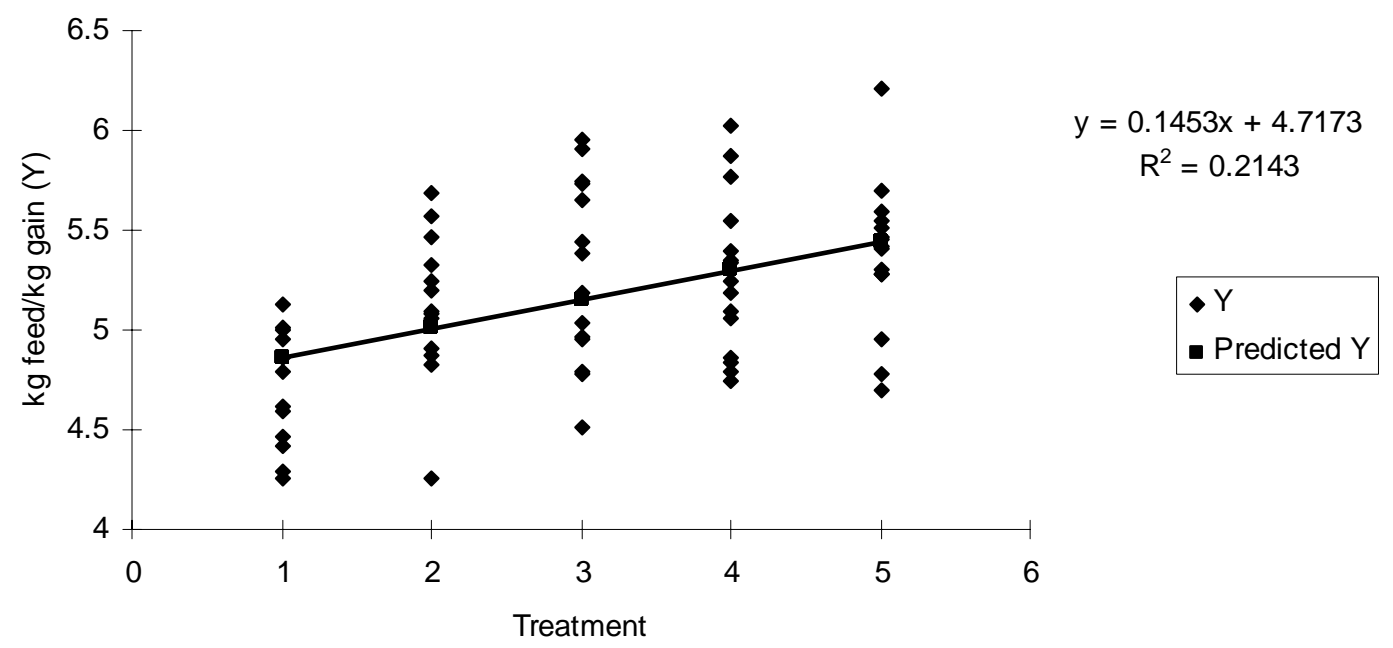

Figure 1 Prediction equation for feed conversion ratio. (Treatments: 1 - Energy source: 100\% hominy chop (HC); 2 - Energy source: 75\% HC and 25\% defatted maize germ meal (DMG); 3 - Energy source: 50\% HC and 50\% DMG; 4 - Energy source: 25\% HC and 75\% DMG; 5 - Energy source: 100\% DMG).

\section{Conclusion}

The different calculation methods correspond satisfactorily. They indicate a $12-14 \%$ lower value for DMG compared with HC in feedlot diets, i.e. better than the industry accepted $15-20 \%$ lower value. This implies that if HC is ZAR 1700 per ton (2008 price), DMG can be priced at ZAR 1480 per ton as the maximum. However, this does not imply that the same value can be used in diets other than cattle feedlot diets. The probability of confounding dietary effects was not investigated, as a direct replacement of hominy chop by DMG was regarded as the main focus of the study. This does, however point to future research possibilities for DMG inclusion in high concentrate diets.

\section{Acknowledgements}

The authors wish to thank Ruto Mills (Pty) Ltd. for their financial support.

\section{References}

AOAC, 2002. Official methods of analysis, $17^{\text {th }}$ ed. Association of Official Analytical Chemists, Inc. Arlington, Virginia, USA.

GenStat for Windows, 2000. Release 4.2. Fifth Ed. VSN International Ltd., Oxford.

Snedecor, G.W. \& Cochran, W.G., 1980. Statistical methods ( $7^{\text {th }}$ Ed.). Iowa State University Press. 